\title{
ARTICLE \\ Topical and systemic pharmacological treatment of atopic dermatitis
}

\author{
A Puterman, ${ }^{1} \mathrm{MB}$ ChB, FCPaed (SA); H Lewis, ${ }^{2} \mathrm{MB}$ ChB, FCPaed (SA); W Sinclair, ${ }^{3}$ MB ChB, MMed (Derm); \\ R J Green, ${ }^{4} \mathrm{MB}$ BCh, DCH, FCP (SA), DTM\&H, MMed, FCCP, PhD, Dip Allergology (SA), DSc \\ ${ }^{1}$ Private practice, Claremont, Cape Town, South Africa \\ ${ }^{2}$ Private practice, Centurion, Pretoria, South Africa \\ ${ }^{3}$ Department of Dermatology, Faculty of Health Sciences, University of the Free State, Bloemfontein, South Africa \\ ${ }^{4}$ Department of Paediatrics and Child Health, Faculty of Health Sciences, University of Pretoria, South Africa
}

Corresponding author: A Puterman (putall@global.co.za)

Topical corticosteroids (TCSs) continue to be the mainstay of atopic dermatitis (AD) treatment. For more than four decades TCSs have provided effective flare control by means of their anti-inflammatory, antiproliferative, immunosuppressive and vasoconstrictive actions. They suppress the release of inflammatory cytokines and act on a variety of immune cells, including T lymphocytes, monocytes, macrophages, dendritic cells and their precursors. Various strengths and formulations of TCSs are available. The extent to which they induce cutaneous vasoconstriction and inhibit inflammation corresponds to their potency.

Topical calcineurin inhibitors (TCIs) (pimecrolimus and tacrolimus) are complex macrocyclic compounds that result in selective inhibition of cytokine transcription in activated T cells. TCIs are registered for short-term and non-continuous chronic treatment of moderate to severe $\mathrm{AD}$ in immunocompetent patients aged $\geq 2$ years. Systemic corticosteroids are frequently used for short-term therapy of severe $\mathrm{AD}$, but their use is controversial. Complementary/alternative therapies have no proven benefit in $\mathrm{AD}$.

S Afr Med J 2014;104(10):714. DOI:10.7196/SAMJ.8870

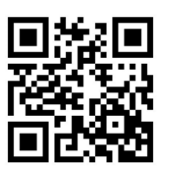

\section{Topical corticosteroids}

Topical corticosteroids (TCSs) continue to be the mainstay of atopic dermatitis (AD) treatment. ${ }^{[1,2]}$ For more than four decades TCSs have provided effective flare control through their anti-inflammatory, antiproliferative, immunosuppressive and vasoconstrictive actions. They suppress the release of inflammatory cytokines and act on a variety of immune cells, including $\mathrm{T}$ lymphocytes, monocytes, macrophages, dendritic cells and their precursors. Various strengths and formulations of TCSs are available. The extent to which they induce cutaneous vasoconstriction and inhibit inflammation corresponds to their potency.

The extensive use of TCSs in clinical practice is supported by an ever-expanding body of clinical trial data, which assists in providing physicians with sensible recommendations for the quantity, frequency, and duration of TCS therapy ${ }^{[3,4]}$ Preparations of very weak or moderate strength are used on the face and genital area, whereas those of moderate or potent strength are used on other areas of the body. ${ }^{[5]}$ Patients should be educated about the different steroid potencies to minimise untoward sideeffects. ${ }^{[6]}$

The vehicle through which the active steroid is delivered plays an important role in absorption and can enhance its efficacy. Generally, ointments are more effective than creams, as the emollient action and occlusive effect result in better skin penetration. Ointments also require fewer preservatives; therefore, the potential for irritant and allergic reactions is lower. Wet wraps and application under occlusion enhance absorption of topical steroids. The various formulations of TCSs available are shown in Table 1.

The corticosteroid preparations currently available in South Africa (SA) are listed below according to potency, with the different formulations given in Table 2.
Topical steroids may be used for 10 - 14 days when the dermatitis is active, followed by 'holidays', with emollients only. TCSs may also be used in bursts of $3-7$ days to treat exacerbations. This rationale may be extended to using potent TCSs for a few days to initiate control, followed by the use of a milder-potency TCS and/or an emollient. ${ }^{[7]}$ For chronic lichenified eczema, frequent applications of potent steroids are required for much longer periods. A possible regimen for TCSs as maintenance treatment for stable disease is 'weekend use', when the product, combined with emollients, is applied on weekend days only, while continuing with emollients only during the rest of the week.

The quantity of TCS that should be used is a common practical problem for patients. The fingertip unit is useful: the index finger from distal crease to fingertip approximates $0.5 \mathrm{~g}$. This aids the monitoring of compliance and use. There is no clear evidence that a twice-daily application of TCS is better than a once-daily application. It may be justified to use once-daily corticosteroids as a first step in all patients with $\mathrm{AD}$, thus reducing cost, improving compliance and reducing side-effects.

There is no convincing evidence for the superior clinical efficacy of corticosteroid-antibiotic combination products compared with corticosteroids alone. When the efficacy of TCSs is reduced, it is thought to be related to disease severity rather than corticosteroid resistance. ${ }^{[8]}$

There are many challenges regarding TCS use, especially in light of steroid abuse, misuse, phobia and side-effects. Adverse effects are well documented and it is important to recognise the side-effects, such as skin atrophy, telangiectasia, hypopigmentation, steroid acne, hirsutism, rosacea and contact sensitisation to the steroid itself. Skin atrophy is not a problem when TCSs are used correctly.

Uncommon systemic effects are the suppression of the hypothalamic-pituitary-adrenal axis, growth retardation, tachyphylaxis, glaucoma, cataract formation and Cushing's syndrome. Over recent years the risk of adverse effects of TCSs 


\section{Table 1. Available topical corticosteroid formulations}

- Water-based lotions: to be used on acute wet dermatitis, scalps of babies, and hairy skin areas in adults

- Alcohol-based lotions: to be used on scalps of older patients

- Shampoo: to be used as short-contact applications for resistant scalp dermatitis in adults

- Creams: to be used on thin subacute lesions, thin skin areas, skin folds, under occlusion (e.g. nappies and occlusive dressings on the face)

- Ointments: to be used on dry subacute lesions

- Fatty ointments: to be used on thick chronic lichenified lesions and thick skin areas

Table 2. Topical corticosteroids available in South Africa

\begin{tabular}{ll}
\hline Corticosteroid & Formulation \\
\hline $\begin{array}{l}\text { Lowest potency } \\
\text { L.5\% hydrocortisone }\end{array}$ & Cream, ointment \\
$1 \%$ hydrocortisone & \\
Moderate potency & Cream, ointment \\
Beclomethasone dipropionate & Cream \\
Clobetasone butyrate & Cream \\
Fluticasone propionate & Cream, ointment \\
Hydrocortisone 17-butyrate & Cream, lipocream, ointment, lotion, emulsifying lotion \\
Methylprednisolone acetonate $1 \%$ & Milk, scalp solution, cream, ointment, fatty ointment \\
Mometasone furoate & Cream, ointment, lotion \\
Potent & \\
Betamethasone valerate & Cream, ointment, solution, scalp solution \\
Fluocinolone acetonide & Cream, ointment, gel \\
Diflucortolone valerate & Cream, fatty ointment, forte ointment \\
Very potent & \\
Clobetasol propionate & Cream, ointment, shampoo, scalp solution \\
Bethametasone dipropionate &
\end{tabular}

has been reduced by optimising application protocols and using newer steroid preparations with improved risk/benefit ratios, e.g. prednicarbate, mometasone furoate, fluticasone and methylprednisolone aceponate. This improved risk/benefit ratio means that the products may be used at a younger age (from the age of four months) and for longer periods (for four weeks continuously in babies and three months in older children and adults). Should these drugs be required at a younger age and for longer periods, as is often the case, the benefit versus risk should be evaluated in each patient and the appropriate formulation carefully selected. Intermittent dosing should be used as far as possible.

The judicious use of TCSs would include short-term appropriate applications as initial monotherapy or in combination with other therapeutic agents that ideally possess complementing mechanisms of action. These drugs could be either systemic agents or topical agents, such as the newer topical calcineurin inhibitors (TCIs). ${ }^{[9]}$

\section{Topical calcineurin inhibitors}

TCIs (pimecrolimus and tacrolimus) are complex macrocyclic compounds that result in selective inhibition of cytokine transcription in activated T cells. Pimecrolimus selectively targets $\mathrm{T}$ cells and mast cells. In contrast to tacrolimus, pimecrolimus has no effect on the differentiation, maturation and function of dendritic cells. Compared with corticosteroids, TCIs do not affect endothelial cells and fibroblasts and therefore do not induce skin atrophy.

TCIs are registered for short-term and non-continuous chronic treatment of moderate to severe $\mathrm{AD}$ in immunocompetent patients aged $\geq 2$ years old. ${ }^{[10,11]}$ Clinically, pimecrolimus lowers the incidence of flares and significantly reduces pruritus.

Both pimecrolimus and tacrolimus are safe and effective in reducing the severity of $\mathrm{AD}$ symptoms in children and adults.

TCIs are frequently associated with a transient burning sensation of the skin, less so with pimecrolimus than tacrolimus. ${ }^{[12]}$ TCIs are not associated with skin atrophy and are therefore useful for the face and intertriginous areas. This can be an advantage in long-term use, and tacrolimus ointment therapy additionally reverses corticosteroid-induced skin atrophy.

In January 2006, the US Food and Drug Administration (FDA) added a boxed warning to TCI labels noting that the longterm safety of these agents has not been established. This warning was in response to widespread off-label use in infants ( $<2$ years) and concerns about a potential cancer risk based on three factors: ( $i$ ) a shared mechanism of action with systemic calcineurin inhibitors; (ii) animal toxicology studies; and (iii) rare post-marketing case reports of malignancy (skin cancer and lymphomas) (http://www.fda. gov/). TCIs are not safe to use in pregnancy or during breastfeeding.

\section{Use of phototherapy}

When topical modalities fail to control AD, phototherapy is the next option. Narrowband ultraviolet B (UVB) light is highly effective and has replaced broadband UVB for treating AD. Patients with acutely inflamed AD do not tolerate UV light well. Therefore, the initial treatment includes immunomodulators, such as cyclosporin or mycophenylate mofetil, or immunosuppressives, such as azathioprine or methotrexate. Once the acute inflammation has settled, UVB therapy may be instituted. ${ }^{[13]}$

\section{Systemic therapy}

Narrow-band UVB, methotrexate and cyclosporin remain reasonable firstline systemic treatments for $\mathrm{AD}$, with mycophenylate and azathioprine as secondline options. ${ }^{[14]}$

\section{Systemic corticosteroids}

Systemic corticosteroids are frequently used for short-term therapy of severe $\mathrm{AD}$, but their use is controversial.

The 2006 Practical Allergy (PRACTALL) consensus group guidelines (http://www. onlinelibrary.wiley.com/doi/10.1111/j.13989995.2006.01153.x/pdf) suggest that in the case of acute flare-ups, patients might benefit from a short course of systemic corticosteroids, but long-term use and use in children should be avoided. 
Table 3. Advice to patients regarding complementary medicines as treatment for atopic dermatitis

- The safety and efficacy of therapies such as herbal medicines, homoeopathy, massage and food supplements have not been adequately investigated in clinical trials

- Caution should be observed with the use of herbal medicines in children

- Topical corticosteroids are sometimes illegally added to some herbal medications

- Liver toxicity can occur with the use of some Chinese herbal medicines

- Emollient treatment should continue, even when complementary therapies are being used

- There may be improvement with regular massage with emollients

- Patients should inform healthcare professionals if they are using complementary therapies

In the rare instances when these agents are prescribed, we prefer the use of prednisolone or prednisone at $1-2 \mathrm{mg} / \mathrm{kg} / \mathrm{d}$. To minimise rebound flares or recrudescence of disease after discontinuation of treatment, we favour tapering after initial control or if improvement is seen after the first 1 - 3 weeks, typically tapering over a period of 1 - 4 weeks, depending on the severity and course of the disease. ${ }^{[15]}$

\section{Antibiotics}

Oral antibiotics do not benefit AD when used for skin that is not clinically infected, but infected dermatitis should be treated with penicillinase-resistant penicillins, cephalosporins or clindamycin. ${ }^{[16,17]}$

\section{Antifungals}

Malassezia sympodialis sensitisation plays an important role in $\mathrm{AD}$ in adults, especially in patients with head and neck dermatitis. IgE-mediated reactions to the fungus can be demonstrated in such patients. Randomised controlled trials (RCTs) with systemic itraconazole ${ }^{[18]}$ and ketoconazole ${ }^{[19]}$ showed significant benefit in such patients.

\section{Intravenous immunoglobulin}

This modality may be used as a last resort in children with severe refractory $\mathrm{AD}$, and is supported by at least one RCT. ${ }^{[20]}$

\section{Interferon gamma}

This expensive treatment may be a useful modality for moderate to severe $\mathrm{AD}$ in children and adults who have a history of recurrent skin infections with herpes simplex, human papillomavirus or molluscum contagiosum. ${ }^{[21]}$

\section{Biological drugs}

Infliximab, efalizumab, tocilizumab and rituximab have been studied in this regard, but no firm recommendations can be provided at this stage.

\section{PPAR-gamma antagonists (thiazolidinediones)}

These antidiabetic drugs also have antiinflammatory properties, e.g. rosiglitazone, and have been retrospectively shown to be beneficial in $\mathrm{AD}^{[22]}$ They also act by improving skin barrier function and thus may be more effective as preventive treatment.

\section{Complementary/ alternative therapies}

These treatments may be defined as forms of therapy or examination that have no scientific basis and for which no effective or diagnostic reliability has been demonstrated by scientific methods. ${ }^{[23]}$ Complementary and alternative medicine refers to the phytotherapies (Chinese herbal medicines, Japanese herbal medicines (Kampo), siddha/ayurveda, tea tree oil and essential fatty acids), homoeopathy, complementary psychotherapy (hypnosis, biofeedback, stress management), acupuncture, bioresonance treatment, balneotherapy, cleansing of the colon with enemas, massage therapy, autologous blood therapy, Reiki and topical streptococcal application. These modalities are becoming increasingly popular, ${ }^{[24]}$ which is understandable when people are faced with an intractable, incurable, highly symptomatic condition be only partially beneficial. Approximately $30-42.5 \%$ of patients with allergies report the use of complementary treatments in Europe; ${ }^{[23,25]}$ these tend to be younger women with a high educational background. ${ }^{[24]}$ No reliable figures or records of treatment methods exist for the treatment of $\mathrm{AD}$ by African traditional healers. It is important to advise patients regarding complementary medicines as treatment for $\mathrm{AD}$ (Table 3). No benefit from probiotics, prebiotics and synbiotics has been demonstrated. ${ }^{[26]}$ for which conventional medicine seems to

\section{References}

1. Hanifin JM, Cooper KD, Ho VC, et al. Guidelines of care for atopic dermatitis, developed in accordance with the American Academy of Dermatology. J Am Acad Dermatol 2004;50:391404. [http://dx.doi.org/10.1016/j.jaad.2003.08.003]

2. Korting HC, Kerscher MJ, Schafer-Korting M. Topical glucocorticoids Korting HC, Kerscher M], Schafer-Korting M. Topical glucocorticoid
with improved benefit/risk ratio: Do they exist? J Am Acad Dermato 1992;27:87-92. [http://dx.doi.org/10.1016/0190-9622(92)70162-9]

3. Callen J, Chamlin S, Eichenfield LF, et al. A systematic review of the safety of topical therapies for atopic dermatitis. Br J Dermatol 2007;156(2):203221. [http://dx.doi.org/10.1111/j.1365-2133.2006.07538.x]

4. Hoare C, Li Wan Po A, Williams H. Systematic review of treatments of atopic eczema. Health Technol Assess 2000;4(37):1-191.

5. McHenry PM, Williams HC, Bingham EA. Management of atopic eczema: Joint Workshop of the British Association of Dermatologists and the Research Unit of the Royal College of Physicians of London. Br Med J 1995;310:843-847.

6. NICE Technology Appraisal Guidance 81. http://www.nice. org.uk/guidance/ta81 (accessed 8 September 2014).

7. Ayres PJ, Hooper G. Assessment of the skin penetration properties of different carrier vehicles for topically applied cortisol. Br J Dermatol 1978;99:307-17. [http://dx.doi. cortisol. Br f Dermatol 1978; $99: 307-17$.
org/10.1111/j.1365-2133.1978.tb02002.x]

8. Ellison JA, Patel L, Ray DW, et al. Hypothalamic-pituitary-adrenal function and glucocorticoid sensitivity in atopic dermatitis. Pediatric 2000;105:794-799. [http://dx.doi.org/10.1542/peds.105.4.794]

9. Del Rosso J, Friedlander SF. Corticosteroids: Options in the era of steroid sparing therapy. J Am Acad Dermatol 2005;53:S50-S58. [http://dx.doi.org/10.1016/j.jaad.2005.04.030]

10. Protopic. Prescribing Information. Deerfield, IL: Astellas Pharma, 2006.

11. Elidel. Prescribing Information. East Hanover, NJ: Novartis Pharmaceuticals, 2006.

12. Kempers S, Boguniewicz M, Carter E, et al. A randomized investigator-blinded study comparing pimecrolimus cream with tacrolimus in the treatment of pediatric patients with moderate atopic dermatitis. J Am Acad Dermatol 2004;51:515525. [http://dx.doi.org/10.1016/j.jaad.2004.01.051]

525. [http://dx.doi.org/10.1016/j.jaad.2004.01.051]
13. Friedmann PS, Arden-Jones MR, Holden CA. Atopic 3. Friedmann PS, Arden-Jones MR, Holden CA. Atopic
dermatitis. In: Burns T, Breathnach S, Cox N, Griffiths C, eds. Rook's Textbook of Dermatology. 8th ed. Chichester, UK Wiley Blackwell Publishers, 2010:24.27-24.28. [http://dx.doi. org/10.1002/9781444317633.ch24]

14. Denby KS, Beck LA. Update on systemic therapies for atopic dermatitis. Curr Opin Allergy Clin Immunol 2012;12(4):421426. [http://dx.doi.org/10.1097/ACI.0b013e3283551da5]

15. Werfel T, Spergel JM, Kiess W, eds. Pediatric and Adolescent Medicine, vol. 15. Basel: Karger, 2011:1-8. [http://dx.doi. org $/ 10.1159 / 000328850]$

16. Abeck D, Mempel M. Staphylococcus aureus colonization in atopic dermatitis and its therapeutic implications. Br J Dermatol 1998;139(Suppl):13-16.

17. Niebuhr M, Mai U, Kapp A, Werfel T. Antibiotic treatment of cutaneous infections with Staphylococcus aureus in patient with atopic dermatitis current antimicrobial resistances and susceptibilities. Exp Dermatol 2008;17:953-957. [http://dx.doi. org/10.1111/j.1600-0625.2008.00734.x]

18. Svejgaard E, Larsen PO, Deleuran M, Ternowitz T, RoedPetersen J, Nilsson J. Treatment of head and neck dermatiti comparing itraconazole $200 \mathrm{mg}$ and $400 \mathrm{mg}$ daily for 1 week with placebo. J Eur Acad Dermatol Venereol 2004;18:445-449. [http://dx.doi.org/10.1111/j.1468-3083.2004.00963.x]

19. Lintu P, Savolainen J, Kortekangas-Savolainen O, Kalime K. Systemic ketoconazole is an effective treatment of atopic dermatitis with IgE-mediated hypersensitivity to yeasts. Allergy 2001;56:512-517. [http://dx.doi.org/10.1034/j.1398Allergy 2001;56:512-517.

20. Jee SJ, Kim JH, Baek HS, et al. Long-term efficacy of intravenous immunoglobulin therapy for moderate to severe childhood immunoglobulin therapy for moderate to severe childhood
atopic dermatitis. Allergy Asthma Immunol Res 2011;3:89-95. atopic dermatitis. Allergy Asthma Immunol

21. Frisch S, Siegfried EC. The clinical spectrum and therapeutic challenge of eczema herpeticum. Pediatr Dermatol 2011;28:4652. [http://dx.doi.org/10.1111/j.1525-1470.2010.01356.x]

22. Behshad R, Cooper KD, Korman NJ. A retrospective case series review of the peroxisome proliferator-activated recepto ligand rosiglitazone in the treatment of atopic dermatitis. Arch Dermatol 2008;144:84-88. [http://dx.doi.org/10.1001/ archdermatol.2007.22]

23. Hughes R, Ward D, Tobin AM, Keegan K, Kirby B. The use of alternative medicine in pediatric patients with atopic dermatitis. Ped Dermatol 2007;24(2):118-120. [http://dx.doi.org/10.1111/ Ped Dermatol 2007;24(2) 1 1525-1470.2007.00355.x]

24. Madsen H, Andersen S, Nielsen RG, et al. Use of complementary alternative medicine among paediatric patients. Eur J Pediatr
ald alternative medicin

2003;162:334-341.
Schafer T. Epidemiology of complementary alternative medicine for asthma and allergy in Europe and Germany. Ann Allergy Asthma Immunol 2004;93(Suppl 1):S5-S10. [http://dx.doi. org/10.1016/S1081-1206(10)61481-0]

26. DiNicola C, Kekevian A, Chang C. Integrative medicine as adjunct therapy in the treatment of atopic dermatitis - the role of traditional Chinese medicine, dietary supplements, and othe modalities. Clinic Rev Allerg Immunol 2013;44:242-253. [http:// dx.doi.org/10.1007/s12016-012-8315-1] 